\title{
Choice, Creativity, and Contingency in Content and Language Integrated Learning
}

\author{
Mark Antony Joseph deBoer \\ Akita International University, Japan
}

\begin{abstract}
In 2010, the Japanese Ministry of Economy, Trade, and Industry mandated universities to create programs to develop students with English communication skills pertinent to their careers and to help students gain workplace competencies such as taking initiative, planning, and working with others. To foster these, a syllabus at Iwate University was conceptualized integrating cross-curricular content with language that put onus on the learners to structure their own learning. This research examines how Japanese first-year students (CEFR A2) collaboratively created a presentation poster using an asynchronous online forum to facilitate a co-constructed task. Data were extracted and analysed from their forum interaction. The results show first, the chronologic relation between posts show how the learners organised their process, second, the relation between their dialogue and poster revisions indicate how they managed the task direction and third, their oscillating roles within their group. Were educators to become more involved in the interaction, educators could gain insights into learner performance. This can foster understanding of the emergent and centrifugal (Bakhtin, 1984) process of learner interaction; particularly in how learners solve language and contentrelated issues as they arise in interaction, using their content to mediate language and vice versa. Raising educator awareness may facilitate the learning process. The focus of the presentation is to highlight the intricacies of learner collaboration and how this benefits research and practice.
\end{abstract}

Keywords: centrifugal discourse; co-construction; educator awareness; learner interaction; process analysis 